\title{
COMPLICATIONS OF TRACHEOSTOMY AND LEADING FACTORS AMONG PATIENTS PRESENTING AT A TERTIARY CARE HOSPITAL, KARACHI
}

Muhammad Fahad Wasim, Naeem Riaz, Sohail Aslam, Syed Muhammad Asad Shabbir Bukhari, Humza Mumtaz, Waseem Ahmed

Pakistan Naval Ship Shifa Hospital, Karachi Pakistan

ABSTRACT

Objective: To look for the complications of tracheostomy and factors correlated with presence of these complications at a tertiary care teaching hospital of Pakistan.

Study Design: Cross-sectional study.

Place and Duration of Study: ENT department, Operation Theater, Emergency department and Critical Care Unit of Pakistan Naval Ship Shifa Hospital, Karachi Pakistan, from Apr to Oct 2019.

Methodology: Sixty nine patients who underwent tracheostomy were included in the analysis. Final decision regarding offering the procedure of tracheostomy to the patient was made by consultant ENT specialist in liaison with the primary treating physician. Patients were assessed for the complications during the procedure, immediately after the procedure, 48 hours after the procedure and one week after the procedure.

Results: Out of sixty nine patients included in the study, $8(11.6 \%)$ patients underwent emergency tracheostomy while 61 $(88.4 \%)$ underwent elective tracheostomy. Ten $(14.5 \%)$ had undergone percutaneous procedure while $59(85.5 \%)$ had undergone open surgical procedure. Hemorrhage was the commonest complication reported followed by dislodgement. With Pearson chi-square test, we found that increasing age (45 years) and emergency tracheostomy had strong association with the presence of complications among the patients undergoing tracheostomy.

Conclusion: Tracheostomy emerged as a safe procedure with mostly minor self-limiting complications. Surgeon performing this procedure should be aware of these common complications and should give information care to the patients prior to the procedure. Patients who are elderly or undergoing emergency tracheostomy should be dealt with special care while doing this life saving procedure.

Keywords: Complications, Correlated factors, Tracheostomy.

This is an Open Access article distributed under the terms of the Creative Commons Attribution License (https://creativecommons.org/licenses/by-nc/4.0/), which permits unrestricted use, distribution, and reproduction in any medium, provided the original work is properly cited.

\section{INTRODUCTION}

Cessation of breathing due to airway obstruction has been one of the most alarming emergencies which warrant an immediate response. Failure in immediate response can lead to serious consequences including the death of the individual ${ }^{1}$. Tracheostomy has been one of the life saving simple procedures which can relieve the patient from the airway obstruction and helps in maintain the airway of the individual ${ }^{2}$. This procedure has been in practice for long time and has evolved with the development in the field of medical science $^{3,4}$.

Tracheostomy has been one of the commonly performed emergency as well as elective procedures in hospitals around the world 5 . Various methods can be used but percutaneous and open surgical methods are widely practiced ${ }^{6}$. Though a lifesaving procedure and sometimes the only option to relieve the airway obstruction; still it has some untoward effects which can be troublesome for the patient in long run ${ }^{7}$. A good

Correspondence: Dr Muhammad Fahd Wasim, Department of ENT, PNS Shifa, DHA Phase-II, Karachi Pakistan

Received: 01 Jan 2020; revised received: 01 Sep 2020; accepted: 02 Sep 2020 knowledge of these complications by the performing surgeon can help him to prevent these and perform it in the safest possible way.

Surgeons, critical care experts and emergency physicians all over the world have tried to evaluate the mortality or morbidity associated with this procedure. Cipriano et al in an overview concluded that there could be immediate, maintenance-related or post-decannulation complications related to the procedure of tracheostomy but these potential complications should not stop the surgeons from performing this life saving procedure after assessment of risks and benefits ${ }^{8}$. Randomized controlled trial comparing the percutaneous and surgical tracheostomy concluded that both the procedures were safe but surgical procedure was linked with more post-operative infection and cosmetic sequel as compared to percutaneous procedure in which bleeding was common complication ${ }^{9}$. A large retrospective study spanning over the period of ten years revolved around the deaths related to the procedure of tracheostomy revealed thatchildren and young adults were more prone to complications of this procedure as compared to elderly. It also revealed some interesting findings that ethnicity as well as education 
of the patient had an effect on overall mortality of patients due to tracheostomy ${ }^{10}$.

No matter which part of the world we belong, this life saving procedure has been in practice in both emergency and planned manner. Few studies have been done in our country as well regarding the routine indications and complications of this procedure. Limited data has been available including the emergency and elective procedures as well as surgical and percutaneous tracheostomies. We therefore planned this study with the rationale assess the complications of tracheostomy and factors correlated with presence of these complications at PNS shifa hospital Karachi.

\section{METHODOLOGY}

This cross-sectional study was conducted at the ENT, Emergency and Critical Care Unit of PNS Shifa Hospital Karachi (IREB letter no: 002) from Apr to Oct 2019. As it is not a very common procedure, so study was done by case series design and all cases which reported during the study time were included in the analysis ${ }^{11,12}$. Sample was gathered by using universal sampling technique. All patients between the age of 1265 years undergoing tracheostomy due to any indication at ENT department, operation theatre, emergency department or critical care unit of PNS Shifa Hospital were included in the study. Final decision regarding offering the procedure of tracheostomy to the patient was made by consultant ENT specialist in liaison with the primary treating physician. All the cases either emergency or elective and surgical or percutaneous after informed consent were included in this analysis. Patients whose exact diagnosis yet to be established were not included in the study. Pregnant patients or those with repeated procedure of tracheostomy in last two weeks were not included in our analysis. Patients with infection on the neck wall were also not included as they were not selected for the procedure due to contraindication. Patients with active coagulopathy issues and deranged INR were also part of the exclusion criteria.

Open surgical technique procedure was performed by giving a $2-3 \mathrm{~cm}$ vertical or horizontal skin incision midway between the sternal notch and thyroid cartilage (approx. level of the second tracheal ring). After division of the skin and underlying platysma, blunt dissection is continued longitudinally. Separation of the strap muscles (i.e., sterno-thyroid, sternohyoid) and lateral retraction exposes the trachea and overlying thyroid isthmus. The isthmus may be mobilized and retracted superiorly or divided. Nearby ves- sels can bleed substantially, and hemostasis is achieved with electro-cautery or suture ligation. Pre-tracheal fascia and fibro-fatty tissue are cleared bluntly and the second to fifth anterior tracheal rings can be visualized. A cricoid hook can provide upward traction on the trachea, thereby improving exposure. Lateral tracheal stay sutures at the third or fourth tracheal rings can provide lateral traction and stabilization and help to define the stoma. A distally based tracheal-wall flap (Bjork flap) may be created or a section of the anterior tracheal wall removed. Pole retractors in the stoma maintain patency and the endotracheal tube is withdrawn under direct vision. A suction catheter placed into the open airway can be used as a guide for tracheostomy tube insertion 13,14 .

Percutaneous dilatational technique is performed by making a $2 \mathrm{~cm}$ transverse skin incision at the level of the second tracheal ring. Blunt vertical dissection is followed by tracheal puncture with a 22-gauge seeker needle followed by an adjacent 14-gauge needle connected to a saline-filled syringe. Subtle differences now distinguish the ways of creating a stoma. The Ciaglia technique uses sequential tracheal dilators (Cook Critical Care Inc.) over the guide-wire. Variations of this include the Per-fit percutaneous tracheostomy introducer set (Smiths Medical) and the Percu-Twist (Meteko Instrument). Alternatively, the Blue Rhino technique (Cook Critical Care Inc.) employs a single large tapered dilator. The Portex Griggs guidewire dilating forceps technique (Smiths Medical) uses dilating forceps over the guide-wire. The Fantoni trans-laryngeal technique (Mallinckrodt) requires retrograde passage of a wire parallel to the ETT. The tube is then attached to the wire. By pulling the wire and using digital counterpressure, the tube is introduced orally and placed through the anterior tracheal wall. Regardless of technique, recent observational data suggest routine radiography has low yield and rarely changes management 16,17 .

Patients were observed for asked for the adverse effects during the procedure and till 48 hours after the procedure. All the complications were entered in a proforma specially designed for this study along with the socio-demographic details of the patients.

Statistics Package for Social Sciences version 24 (SPSS-24) was the software used to process all the data and carry out the necessary analysis. Frequency and percentage for the quantitative variables were calculated especially the complications faced by the patients during the procedure. Pearson chi-square test (with $p$ - 
values $\leq 0.05$ as significant) was performed to see the association of different variables with the presence of complications among the sample population.

\section{RESULTS}

A total of 71 patients were advised tracheostomy by ENT doctors or emergency physicians or critical care physicians. One was pregnant andone patienthad necrotizing infection at anterior aspect of neck. Out of 69 patients included in the final analysis 40 (57.9\%) were male and $29(42.1 \%)$ were female. Male to female ratio was 1.4:1. Mean age of patients who underwent tracheostomy and included in this analysis was 36.23 \pm 2.471 years. Fifty nine $(85.5 \%)$ patients underwent open surgical tracheostomy and percutaneous procedure was performed on only $10(14.5 \%)$ patients. Hemorrhage $(8.6 \%)$ was the commonest complication faced by the patients followed by dislodgement (5.8\%) (tableI). Pearson chi-square analysis showed that increasing age and emergency tracheostomy had significant relationship with presence of complications among the patients undergoing tracheostomy in our study (table-II).

\begin{tabular}{|c|c|}
\hline Variable & n (\%) \\
\hline \multicolumn{2}{|l|}{ Age (years) } \\
\hline $\begin{array}{l}\text { Mean } \pm \text { SD } \\
\text { Range (min-max) }\end{array}$ & $\begin{array}{c}36.23 \pm 2.47 \text { years } \\
12-65 \text { years }\end{array}$ \\
\hline \multicolumn{2}{|l|}{ Gender } \\
\hline $\begin{array}{l}\text { Male } \\
\text { Female }\end{array}$ & $\begin{array}{l}40(57.9 \%) \\
29(42.1 \%)\end{array}$ \\
\hline \multicolumn{2}{|c|}{ Complications During or After Tracheostomy } \\
\hline $\begin{array}{l}\text { Hemorrhage } \\
\text { Dislodgement } \\
\text { Infection } \\
\text { Surgical Emphysema } \\
\text { Tube Blockade }\end{array}$ & $\begin{array}{l}06(8.6 \%) \\
04(5.8 \%) \\
03(4.3 \%) \\
01(1.4 \%) \\
02(2.9 \%) \\
\end{array}$ \\
\hline \multicolumn{2}{|l|}{ Types of Tracheostomy } \\
\hline $\begin{array}{l}\text { Open Surgical Method } \\
\text { Percutaneous Method }\end{array}$ & $\begin{array}{l}59(85.5 \%) \\
10(14.5 \%) \\
\end{array}$ \\
\hline
\end{tabular}

\section{DISCUSSION}

Liaison in various fields of medicine serves as a key to effective management of the patient. Lifesaving modalities may be domain of one specialty but needed by almost all the specialists in managing the patients with various life threatening conditions. Tracheostomy has been one such procedure which has been in use for years to manage the patients with airway obstruction and difficulty in breathing ${ }^{2}$. It has been debatable that who should be the ideal person in the hospital setting to perform this procedure. ENT specialist, anesthetist, critical care experts and emergency physicians have been performing this procedure in routine in all parts of the world ${ }^{11-13}$. Critical care and emergency medicine are toddler as specialties in our part of the world so most of the burden has been shared by ENT experts and anesthetist for performing the tracheostomy in our setup.We conducted this study mainly on the tracheostomies performed by ENT specialist in all the settings of our hospital in order to assess the complications of this procedure and factors correlated with presence of these complications at our tertiary care teaching hospital of Pakistan Navy.

Table-II: Relationship of variables with presence of complications.

\begin{tabular}{|c|c|c|c|}
\hline $\begin{array}{l}\text { Factors } \\
\text { Total } \\
n=69\end{array}$ & $\begin{array}{c}\text { No } \\
\text { Complication } \\
\text { n (\%) } \\
53(76.8)\end{array}$ & $\begin{array}{c}\text { Presence of } \\
\text { complication } \\
n(\%) \\
16(23.2)\end{array}$ & $\begin{array}{c}p- \\
\text { value }\end{array}$ \\
\hline \multicolumn{4}{|l|}{ Age } \\
\hline $\begin{array}{l}12-45 \text { years } \\
>45 \text { years }\end{array}$ & $\begin{array}{l}29(54.7) \\
24(45.3)\end{array}$ & $\begin{array}{l}02(12.5) \\
14(87.5)\end{array}$ & 0.003 \\
\hline \multicolumn{4}{|l|}{ Gender } \\
\hline $\begin{array}{l}\text { Male } \\
\text { Female }\end{array}$ & $\begin{array}{l}30(56.6) \\
23(43.4)\end{array}$ & $\begin{array}{l}10(62.5) \\
06(27.5)\end{array}$ & 0.675 \\
\hline \multicolumn{4}{|c|}{ Emergency / Elective Procedure } \\
\hline $\begin{array}{l}\text { Elective } \\
\text { Emergency }\end{array}$ & $\begin{array}{c}51(96.2) \\
02(3.8)\end{array}$ & $\begin{array}{l}10(62.5) \\
06(27.5)\end{array}$ & $<0.001$ \\
\hline \multicolumn{4}{|c|}{ Types of Tracheostomy } \\
\hline $\begin{array}{l}\text { Open surgical } \\
\text { method } \\
\text { Percutaneous } \\
\text { method }\end{array}$ & $\begin{array}{l}47(88.7 \\
06(11.3)\end{array}$ & $\begin{array}{l}12(75) \\
04(25)\end{array}$ & 0.173 \\
\hline
\end{tabular}

This procedure emerged as a relatively safe procedure in our study. Mortality was zero as no patient died as a consequence of this procedure. Most of the complications were temporary and manageable in the hospital setting. Intra operative or early post-operative hemorrhage was the commonest complication which our study participants faced. Tracheostomy tube dislodgment was the second most common complication faced by the target population. These results also have been generated by similar studies done in the past by Silvester et al in 2006 and Megha et al in 2017 in other parts of the world ${ }^{9,17}$. As this procedure is a lifesaving procedure and usually performed in emergency with patients having multiple co-morbid so complications like hemorrhage can be expected in these patients. Moreover these patients especially those in critical care settings can undergo delirium or acute confused state and tube dislodgement can occur in such state. Knowledge of these complications can help in early recogni- 
tion and prompt treatment, thus increasing the safety of this life saving procedure.

Increasing age of the patients in this study emerged as predictor for the presence of complications. Variable results have been reported in the past literature. Some conclude that age has no influence on presence of complications and others conclude that pediatric and geriatric both populations may be at more risk. Starzl et al. in 1959 and Mehta et al in 2017 due to huge difference in time have shown entirely different findings in this regard ${ }^{18-20}$. More studies with sophisticated study design and long term follow up may be helpful in generating accurate data in this regard.

Emergency tracheostomy was performed on very less number of patients but still it was significantly linked with the presence of complications. Similar findings have been reported in the study performed by Mehta et al in 2017 with similar design ${ }^{20}$. This is quite understandable as immediate threat to life warrants this procedure in emergency and the treating physician could not be as prepared as he could be in elective setting. More longitudinal research can give us data for the factors which can improve the safety even in emergency procedure.

\section{CONCLUSION}

Tracheostomy emerged as a safe procedure with mostly minor self-limiting complications. Surgeon performing this procedure should be aware of these common complications and should give information care to the patients prior to the procedure. Patients who are elderly or undergoing emergency tracheostomy should be dealt with special care while doing this life saving procedure.

\section{CONFLICT OF INTEREST}

This study has no conflict of interest to be declared by any author.

\section{REFERENCES}

1. Gilani A, Black JO, Weinman JP, Galambos C. Sudden death due to complete airway obstruction by bronchial casts. Am J Respir Crit Care Med 2019; 199(3): 380.

2. Alabi BS, Afolabi OA, Dunmade AD, Omokanye HK, Ajayi IO. Indications and outcome of tracheostomy in Ilorin, North Central Nigeria: 10 years review. Ann Afr Med 2018; 17(1): 1-6.
3. Bach JR. A short history of medical expert guidelines and how they pertain to tracheostomy tubes and physical medicine and rehabilitation. Am J Phys Med Rehabil 2019; 98(7): 622-26.

4. Bontempo LJ, Manning SL. Tracheostomy emergencies. Emerg Med Clin North Am 2019; 37(1): 109-19.

5. Cheung NH, Napolitano LM. Tracheostomy: epidemiology, indications, timing, technique, and outcomes. Respir Care 2014; 59(6): 895-915.

6. Rashid AO, Islam S. Percutaneous tracheostomy: a comprehensive review. J Thorac Dis 2017; 9(Suppl-10): S1128-38.

7. Shin B, Kim K, Jeong BH, Eom JS, Song WJ, Kim H. Clinical implications of differentiating between types of post-tracheostomy tracheal stenosis. J Thorac Dis 2017; 9(11): 4413-23.

8. Cipriano A, Mao ML, Hon HH, Vazquez D, Stawicki SP, Sharpe $\mathrm{RP}$, et al. An overview of complications associated with open and percutaneous tracheostomy procedures. Int J Crit Illn Inj Sci 2015; 5: 179-88.

9. Silvester W, Goldsmith D, Uchino S, Bellomo R, Knight S, Seevanayagam S, et al. Percutaneous versus surgical tracheostomy: A randomized controlled study with long-term followup. Crit Care Med 2006; 34(8): 2145-52.

10. Gilyoma JM, Balumuka DD, Chalya PL. Ten-year experiences with Tracheostomy at a University teaching hospital in Northwestern Tanzania: A retrospective review of 214 cases. World J Emerg Surg 2011; 6(1): 38.

11. Zochios V, Casey J, Parhar K, Vuylsteke A. Timing of tracheostomy and associated complications in cardiothoracic intensive care patients. Heart Lung Vessel 2015; 7(2): 179-80.

12. Bhatti AB, Iqbal H, Hussain R, Syed AA, Jamshed A. Tracheotomy in cancer patients: experience from a cancer hospital in Pakistan. Indian J Surg 2014; 77(Suppl-3): 906-09.

13. Ahmed Z, Mahida KH, Huma ZE, Muhammad T. Complications of open surgical tracheostomies and their management - our experience. Pak Armed Forces Med J 2018; 68 (6): 1642-47.

14. Walts PA, Murthy SC, DeCamp MM. Techniques of surgical tracheostomy. Clin Chest Med 2003; 24(3): 413-22.

15. Mehta C, Mehta Y. Percutaneous tracheostomy. Ann Card Anaesth 2017; 20(Suppl): S19-25.

16. Singh J, Sing RF. Performance, long-term management, and coding for percutaneous dilational tracheostomy. Chest 2019; 155(3): 639-44.

17. Megha AK, Prashant NK, Surendra HG, Sneha VB, Aniket B. A prospective study of complications of tracheostomy and management in tertiary care hospital in rural area. Glob J Oto 2017; 5(3): 555667.

18. Starzl TE, Meyer WH, Farrell JJ. Prophylactic tracheostomy in aged and poor risk general surgical patients. J Am Med Assoc 1959; 169(7): 691-95.

19. Kawale MA, Keche PN, Gawarle SH, Bhat SV, Buche A. A prospective study of complications of tracheostomy and management in tertiary care hospital in rural area. Int J Otorhinolaryngol Head Neck Surg 2017; 3: 687-92.

20. Mehta AK, Chamyal PC. Tracheostomy complications and their management. Med J Armed Forces India 2017; 55(3): 197-200. 